\title{
TPARAMEDICINE
}

Irish Journal of Paramedicine

Official journal of the Irish College of Paramedics

Volume 1 Issue 2

December 2016

\section{Toward an international paramedic research agenda}

Brian Maguire Dr.PH

Central Queensland University, Australia.

Peter O’Meara $\mathrm{PhD}$

La Trobe University, Victoria, Australia.

Andy Newton $\mathrm{PhD}$

South East Coast Foundation Ambulance NHS Trust, United Kingdom

\section{Recommended Citation}

Maguire B, O’Meara P and Newton A. Toward an international paramedic research agenda. Irish Journal of Paramedicine. 2016 Dec; 1(2)

This is an Open Access article distributed under the terms of the Creative Commons Attribution-Non-Commercial-ShareAlike 4.0 International (http://creativecommons.org/licenses/by-nc-sa/4.0/), which permits use, distribution, and reproduction in any medium, provided the original work and any attributes thereof are properly cited, are distributed under the same licence, and that the work is not used for commercial purposes.

Follow the Irish Journal of Paramedicine online at www.irishparamedicine.com, on Twitter (iishiparamed) and on Facebook. 
COMMENTARY

\title{
Toward An International Paramedic Research Agenda
}

\author{
Brian J. Maguire Dr.PH ${ }^{1}$, Peter O'Meara $\mathrm{PhD}^{2}$, Andy Newton $\mathrm{PhD}^{3}$
}

1. Central Queensland University, Queensland, Australia. 2. La Trobe University, Victoria, Australia. 3. South East Coast Foundation Ambulance NHS Trust, United Kingdom

Correspondence: Prof. Brian J. Maguire, Central Queensland University, Rockhampton North, Building 6, Rockhampton, Qld 4702. Email: $\underline{\text { b.maguire@.cqu.edu.au }}$

Around the world the emergency medical services (EMS) profession has made tremendous strides over recent decades. We have become more professional, have a rapidly growing proportion of paramedics who are university qualified, our practice has become more evidence-based, and a growing number of paramedics are completing graduate-level programs and going on to conduct their own research. In some countries, such as South Africa, the UK, and currently in Australia, this rise in professionalisation has resulted in paramedics becoming independently registered health care practitioners. As a profession we have much to celebrate when we consider these accomplishments.

These trends are, to some extent, related to the changing demand in terms of the patient case mix, itself a consequence of changes in population profile, epidemiology and, in some instances, also related to the health care systems EMS operates within. They also reflect the broader roles that EMS is creating and accepting; these roles require more from paramedics in relation to clinical decision making, interprofessional working, intellectual understanding, technical skills, research and much more.

We have seen other professions develop along similar pathways. A century ago physicians were trained in hospital basements and practiced procedures that had little evidence to ensure their quality or effectiveness. A half century ago nurses were largely trained in hospital basements and again had little research to justify their practices. Members of those professions recognized that the only way out of the basement was through the university. Members of those and other health professions took it upon themselves to make a university degree a requirement to enter practice. They recognized that a university degree was a key requirement of professionalism. Today we could not imagine a physician without a university degree and almost all new nurses and many allied health professionals are now graduates of university programs.

These professions also recognize the necessity of conducting their own research as an essential cornerstone of their professional status and identity. Physicians do not rely solely on biologists, chemists or physicists to conduct medical research. Instead, physicians, with the support and encouragement of their profession, are expected to pursue graduate research degrees and then work in university environments to conduct the research needed by their profession. In fact, over the past few decades it has become even more discipline-specific. Emergency medicine physicians, for example, no longer rely on cardiologists or surgeons to conduct emergency medicine related research.

Alongside professionalism comes the recognition of the necessity to take more research responsibility and there is a particular need to do so in EMS where the research base was once described as 'scanty' by Callaham.(1) Over the past few years there have been some local efforts to develop and pursue EMS-specific research agendas. In Australia for instance, paramedic academics are pursuing the development of a national paramedic research agenda and associated priorities to "assess the progress of paramedicine research in Australia and New Zealand; map the research capacity of the paramedicine discipline, paramedic services, universities and professional organisations; identify current strengths and opportunities; make recommendations to capitalize on opportunities; and, identify research priorities." (2)

In the U.S., the National Highway Traffic Safety Agency (the lead EMS agency in the U.S.) commissioned a project to develop EMS research priorities. Their recommendations include: develop a large cadre of career EMS investigators; create EMS research Centers of Excellence; lobby federal agencies to commit to EMS research; encourage states, corporations, and charitable foundations to support EMS research; connect research and operations so that research results can be applied; as a profession recognize that our procedures should be evidence based; create standardizations in data collection; and, develop EMS-specific ethics strategies.(3)

In the Netherlands, a similar process identified the leading EMS research priorities as: "Non-conveyance to the hospital (ranked highest); Performance measures for quality of care; Hand over/registration/exchange of patient data; Care and task substitution; Triage; Assessment of acute neurologic signs \& symptoms; Protocols and protocol adherence; Immobilisation; and Open/secure airway."(4)

In 2006, Canadian EMS leaders recognized that "EMS does not currently possess the research base and data collection capability required to systematically evaluate and provide guidance for the improvement of overall levels of care. They found that EMS research continues to be underfunded and neglected. It is constrained by funding considerations, lack of a central data repository, and underdeveloped technology infrastructure." They went on to note that objective standards and protocols "is a critical success factor in the provision of higher quality care."(5) A presumably more recent, but undated, document from the Paramedic Chiefs of Canada notes their priorities as including: "Strengthen research partnerships between EMS 
academic centres, systems, regulators, educators and national associations; Increase funding opportunities for EMS research infrastructure and studies; Provide scholarships for EMS providers, managers and physicians to take researchbased graduate degrees; EMS systems administrators should budget for research projects during annual strategic planning; and, the EMS Research Agenda needs to be viewed as an ongoing project. An implementation, evaluation and renewal plan should be designed and this process should include mapping gaps in EMS research."(6)

In 2008, the University of Limerick published a national prehospital research agenda for Ireland where they noted the importance of research and called for a research strategy to guide building a productive, functioning research community in the prehospital arena.(7)

In the United Kingdom there has been substantial investment in pre-hospital research. The Medical Care Research Unit in Sheffield described international themes in a survey of international best practice published in 2009.(8) In 2016, the National Institute for Health Research (NIHR) published a themed review summarising relevant completed and current research that they have funded over the last 10 years. This review highlights 40 studies encompassing complex multicentre clinical trials, evaluations of service delivery and organisation, qualitative studies focussed on paramedic decision making and programmes to develop EMS quality and performance measures. A common feature of the research presented is the multidisciplinary and collaborative approaches adopted which bring together EMS providers, clinicians and academic partners and the emergence of a new cadre of research paramedics who are crucial to the success of this world class research. The review demonstrates the enormous progress made in this field in a relatively short space of time.(9)

\section{Where we need to go from here}

The priorities for us, as a profession, include setting systems in place to support not only medical based research but also operations, education and systems research that will ensure that our operations, education and systems are based on the best evidence for effective, efficient and safe delivery of out of hospital care. The same rigour that is applied to ensure that the drugs we administer are safe and effective need to be used to ensure that our operations and practices are safe and effective.

We must establish systems for EMS research that result in university-affiliated EMS professionals leading and conducting research in collaboration with EMS agencies and in partnership with other relevant disciplines, such as public health, statisticians, health economists and other specialist researchers. Every EMS agency that has an agency-based research department separate from a university EMS education program is hurting the profession. As Irish emergency medicine physicians recently noted: "a nationally focused research agenda is required to solve the main challenges facing the delivery of optimal patient care in Irish EDs".(10) So it is with EMS. We must form strong research consortiums if we are to hope to conduct research that will inform and create an increasingly professional EMS profession and that, at the same time, will support and encourage the long term sustainability of EMS researchers.

As a profession we must: develop systems for the development of national and international research agendas that will meet the needs of EMS agencies, EMS researchers, patients and local governments; create support mechanisms for paramedics to pursue research higher degrees; and, develop partnerships between university EMS programs and EMS agencies that facilitate funding and resources to support research.

Working together we can form international EMS research consortiums that will help both address the needs of today and enable us to anticipate and prepare for the needs of tomorrow.

Author contributions BM, POM and AN were authors of the manuscript, and all contributed to the final editing.

Source of support/funding: None.

Conflict of interest: POM an Editorial Board member of the IJP.

Provenance and review: Commissioned, not peerreviewed.

\section{References}

1. Callaham M. (1997) Quantifying the scanty science of prehospital emergency care. Annals of Emergency Medicine;30(6):785-790.

2. O’Meara P, Maguire B, Jennings P, Simpson P. (2015) Building an Australasian paramedicine research agenda: a narrative review. Health Research Policy and Systems;13 (1): 1 .

3. U.S. National Highway Traffic Safety Administration. (2001) National EMS Research Agenda. Available at. http:// ems.gov/pdf/EMSResearchAgenda.pdf. Accessed August 31, 2013.

4. van de Glind I, Berben S, Zeegers F, Poppen H, Hoogeveen M, Bolt I, van Grunsven P, Vloet L. (2016) A national research agenda for pre-hospital emergency medical services in the Netherlands: a Delphi-study. Scandinavian Journal of Trauma, Resuscitation and Emergency Medicine;24(1):1.

5. EMS Chiefs of Canada. (2006) Future of EMS in Canada: Defining the New Road Ahead. Available at. http:// www.emscc.ca/. Accessed 13 May 08.

6. EMS Chiefs of Canada. Canadian National EMS Research Agenda. Available at. http://www.paramedicchiefs.ca/docs/ nra/national-research-agenda-non-ineractive.pdf. Accessed 2 Nov 16.

7. O'Donnell C, O'Reilly S. (2008) A National Prehospital Research Strategy. University of Limerick.

8. Snooks H, Evans A, Wells B, Peconi J, Thomas M, 
Woollard M, Guly H, Jenkinson E, Turner J, Hartley-Sharpe C. (2009) What are the highest priorities for research in emergency prehospital care? Emergency Medicine Journal;26 (8):549-550. Accessed 2 Nov 16.

9. National Institute for Health Research (2016) Research for Ambulance Services. Available at. http://www.dc.nihr.ac.uk/ themed-reviews/care-at-the-scene.htm. Accessed 15 Nov 2016.

10. Doyle M. (2015) The Health Research Stakeholder Consultation on a new Strategy for Science, Technology and Innovation: Submission from the Irish Association for Emergency Medicine (IAEM) on Emergency Medicine Research in Ireland. Irish Association for Emergency Medicine. Available at. https://www.djei.ie/en/Consultations/ Consultations-files/Irish-Association-for-Emergency-

Medicine.pdf. Accessed 2 Nov 16.

This is an Open Access article distributed under the terms of the Creative Commons Attribution-Non-Commercial-ShareAlike 4.0 International (http:// creativecommons.org/licenses/by-nc-sa/4.0/), which permits use, distribution, and reproduction in any medium, provided the original work and any attributes thereof are properly cited, are distributed under the same licence, and that the work is not used for commercial purposes. Content copyright remains with the authors, who grant the IJP a licence to reuse and distribute. 